\title{
A crosscut survey on reproductive health in Lithuanian childhood cancer survivors
}

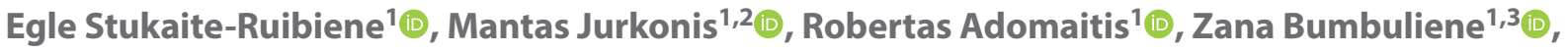

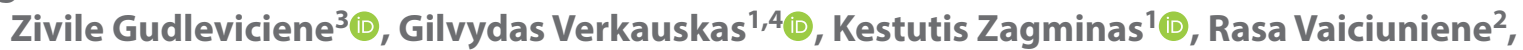 \\ Jelena Rascon ${ }^{1,2}$ (1) \\ ${ }^{1}$ Vilnius University, Faculty of Medicine, Vilnius, Lithuania \\ ${ }^{2}$ Center for Pediatric Oncology and Hematology, Vilnius University, Vilnius, Lithuania \\ ${ }^{3}$ Center of Obstetrics and Gynecology, Vilnius University, Vilnius, Lithuania \\ ${ }^{4}$ Center of Children's Surgery, Orthopedics and Traumatology, Vilnius University, Vilnius, Lithuania
}

\begin{abstract}
Objectives: Sexual dysfunction was reported to compromise the quality of life in childhood cancer survivors. The aim of our study was to evaluate the reproductive health in long-term pediatric cancer survivors by conducting a crosscut survey. Material and methods: Childhood cancer survivors over 18 years of age, who were in remission for more than 5 years, were invited to complete a gender-specific questionnaire surveying on their reproductive health. Demographic and treatment data were retrieved from their medical records. Treatment modalities were reviewed for its potential gonadotoxicity. Results: 34 (17 males and 17 females, respectively) from 346 addressed survivors (9.8\%) completed the questionnaire. Median age and follow-up after diagnosis was 27 (18-35) and 14 (3-25) years, respectively. Some respondents reported sexual concerns: $11.8 \%$ males experienced problems with penetration, two males $(11.8 \%)$ who underwent semen analysis were found to be azoospermic. Similarly, $11.8 \%$ females reported delayed puberty, the average age of menarche was 14 (12-17) years, $29.4 \%$ females reported irregular menstrual cycles. Cyclophosphamide equivalent dose (CED) differed significantly between the patients treated for leukemia, lymphoma and solid tumors ( 3000 vs 4352 vs $6660 \mathrm{mg} / \mathrm{m}^{2}$, respectively, $p=0.014$ ).

Conclusions: Low prevalence of sexual dysfunction, fertility related disorders or delayed puberty in childhood cancer survivors was found. However, the results should be interpreted with caution taking into account a low response rate.
\end{abstract}

Key words: late effects; long-term survivors; pediatric cancer; reproductive health; sexual dysfunction

Ginekologia Polska 2021; 92, 4: 262-270

\section{INTRODUCTION}

Over the last few decades, a long-term survival rate after pediatric cancer has improved dramatically and nowadays exceeds $80 \%$ in most European countries [1]. High cure rates imply a constantly growing population of childhood cancer survivors. As a consequence, research activities are focused not only on overcoming resistant malignancies but also on the well-being of the cured persons who are at the risk for frailty, and suboptimal quality of life [2].

A healthy reproductive system is a cornerstone of the quality of life in young adult survivors. Sexual dysfunction was reported to be one of the most important side effects of pediatric cancer treatment [3]. Treatment intensity depends on cancer type, localization, spread of the disease (metastases) and other risk factors. Most patients are exposed to combined treatment including chemotherapy, surgery, radiotherapy, less frequently high-dose chemotherapy prior to hematopoietic stem cell transplantation and the immune therapy. All the approaches, used separately or in combination, could potentially have an adverse long-term effect on fertility $[4,5]$. It is crucial to inform every patient (parents or guardians in pediatric setting) about the potential adverse effect of cancer treatment on the reproductive health and options for fertility preservation. The majority of childhood cancer survivors perceive they had not been provided sufficient information about reproductive health and had never underwent fertility testing $[6,7]$.

Studies have shown that in females chemotherapy regimens containing high-dose alkylating agents and abdominal/pelvic radiotherapy affected the gonadal function, 
and were associated with delayed puberty, premature ovarian insufficiency and follicular atresia, premature menopause and infertility [8]. In males, infertility was reported to be related to the use of alkylating agents, testicular radiation, or cranial irradiation [4]. Certain concomitant chemotherapy agents such as cisplatin, carboplatin, increase the risk of infertility in childhood cancer survivors [9-11].

Cumulative exposure to alkylating agents can be quantified using the cyclophosphamide equivalent dose (CED), as described by Green et al. [12] that compares the drugs based on the hematological toxicity. The adoption of the CED allows evaluation of the relationship between hematological toxicity and alkylating agent related late outcomes, such as infertility. The advantage of the CED is its derivation from actual drug doses rather than dependence on a drug dose distribution specific to a single population [12]. CED $\geq 4000 \mathrm{mg} / \mathrm{m}^{2}$ is associated with a risk of infertility, while CED $\geq 8000 \mathrm{mg} / \mathrm{m}^{2}$ is most likely to cause infertility leading to premature ovarian insufficiency in females [13] and increased chance of oligospermia and azoospermia in males [14].

The purpose of our study was to evaluate reproductive health in pediatric cancer survivors who were in a long-term remission and were in reproductive age. The research aimed at elucidating personal perception of the study participants with regard to their reproductive health, thus a surveying approach was adopted. Additionally, the exposure to gonadotoxic therapies reviewed was retrospectively.

\section{MATERIAL AND METHODS}

A single-center cross-sectional study was carried out from December 2016 to January 2018. All subjects gave their informed consent for inclusion before they participated in the study. The study was conducted in accordance with the Declaration of Helsinki. The study population included childhood cancer survivors treated at the Center for Pediatric Oncology and Hematology, Vilnius University Hospital Santaros Klinikos. The inclusion criteria were defined as 1) age $18+$ years as of December 2016;2) childhood cancer (ICD-O-10 C00-C96) diagnosed in 1982-2011;3) In remission $5+$ years since diagnosis in December 2016. The study was approved by the Vilnius Regional Committee of Biomedical Research (Approval No.158200-16-873-385).

Survivors who met the inclusion criteria were identified at the institutional database. The identified cohort was contacted by regular certificated mail to the postal address available in the medical records: an invitation to participate in the study, an informed consent form, and a questionnaire were sent to each consignee. The respondents who signed the informed consent, completed the questionnaire, and returned it to the study center were included into the final analysis.
Two gender-specific questionnaires were elaborated by a multidisciplinary team of pediatric oncologist, obstetrician-gynecologist, urologist and clinical embryologist. The participants were invited to answer 17-18 questions regarding sexual health, ability to conceive, marital status/partnership (Supp. 1 available on https://journals.viamedica.pl/ginekologia_polska/issue). As a complementary service a consultation of a gender-appropriate reproductive health specialist was offered to all contacted survivors. Additionally, a summary of the study results was offered to be shared upon request.

The answers were collected from the completed questionnaires and analyzed anonymously. Baseline characteristics and treatment-related data (diagnosis, type of chemotherapy drugs used and dosages, information on radiotherapy and surgical treatment) were retrieved from the patients' paper or electronic medical records.

The exposure to alkylating agents was assessed by CED calculation using the equation described by Green et al. [12]: CED $\left(\mathrm{mg} / \mathrm{m}^{2}\right)=1.0$ (cumulative cyclophosphamide dose, $\mathrm{mg} / \mathrm{m}^{2}$ ) +0.244 (cumulative ifosfamide dose, $\mathrm{mg} / \mathrm{m}^{2}$ ) +0.857 (cumulative procarbazine dose, $\mathrm{mg} / \mathrm{m}^{2}$ ) +14.286 (cumulative chlorambucil dose, $\mathrm{mg} / \mathrm{m}^{2}$ ) +15.0 (cumulative BCNU dose, $\mathrm{mg} / \mathrm{m}^{2}$ ) +16.0 (cumulative CCNU dose, $\mathrm{mg} / \mathrm{m}^{2}$ ) +40 (cumulative melphalan dose, $\left.\mathrm{mg} / \mathrm{m}^{2}\right)+50$ (cumulative thioteps dose, $\left.\mathrm{mg} / \mathrm{m}^{2}\right)+100$ (cumulative nitrogen mustard dose, $\mathrm{mg} / \mathrm{m}^{2}$ ) +8.823 (cumulative busulfan dose, $\mathrm{mg} / \mathrm{m}^{2}$ ). Cumulative treosulfan dose was not included in the original computation. The dacarbazine cumulative dose was calculated as a single drug - being quite different from other classical alkylating agents, it is not included in CED calculation. In addition, a cumulative dose of platinum compounds (carboplatin and cisplatin) was evaluated. Data on the surgery and radiotherapy for potential involvement of gonadal areas were revised. The data evaluation time-point was January 2018.

Demographic and treatment-related characteristics were assessed using descriptive statistics. The median-test was used to compare the medians of cumulative CED between different types of childhood cancer. SPSS ver. 17 (IBM Corp., Armonk, NY) was used for all quantitative analyses, p-value less than 0.05 was considered to be significant.

\section{RESULTS}

In total 346 childhood cancer survivors [195 (56.4\%) males and 151 (43.6\%) females] matched the inclusion criteria (Supp. 2 available on https://journals.viamedica. $\mathrm{pl} /$ ginekologia_polska/issue). In contrast to the expectations, the response rate was very low - only 34 (9.8\%) survivors answered the questions. One hundred twenty (34.7\%) consignees appeared to be unavailable: in 99 (28.6\%) cases the letters were not reclaimed at the post office, in 19 (5.5\%) 
Table 1. Baseline characteristic of the study participants

Variables

\section{Current age (years)}

Median

(min-max)

Age at cancer diagnosis (years)

Median

(min-max)

Follow-up time (years)

Median

(min-max)

\section{Cancer type}

Leukemia, myeloproliferative disorders, myelodysplasia $n,(\%)$

Lymphomas and reticuloendothelial neoplasms n, (\%)

Tumors in the Central Nervous System n, (\%)

Neuroblastoma and other peripheral nerve sheath tumors n, (\%)

Osteosarcoma and other bone malignancies $\mathrm{n},(\%)$

Other epithelial tumors and melanoma $n,(\%)$

*according to ICCC-3 (International classification of childhood cancer)

cases the postal address was no longer valid, 2 (0.6\%) patients had died. However, the majority of the invited survivors 190 (54.9\%) received the invitation but refrained from sharing their answers. None of them wished to take the opportunity to see a specialist in reproductive health.

Thirty-four (9.8\%) respondents (17 males and $17 \mathrm{fe-}$ males) were included into the final analysis. The median age at the time of evaluation was $27(18-35)$ years, meanwhile the one at cancer diagnosis - 13 (2-18) years. The age did not differ between males and females (Tab. 1). Leukemia and lymphoma were the most common types of malignancies among the respondents [13 (36.1\%) and 15 (44.1\%), respectively] whereas only 6 (17.6\%) were affected by solid tumors. All patients were diagnosed with only one type of cancer, there were no cases of a second malignant neoplasm. The distribution of cancer types across survivors who met the inclusion criteria and were invited to participate in the study showed a slight predominance of leukemia as compared to the study cohort: among 346 survivors, 165 (47.7\%) were diagnosed with leukemia, 122 (35.3\%) with lymphoma, and only 59 (17.1\%) with solid tumors (Supp. 2 available on https://journals.viamedica.pl/ginekologia_polska/issue).

Most of the survivors were treated with chemotherapy ( $n=33,97 \%$ ), radiotherapy was delivered to 18 patients $(54.5 \%)$, six (17\%) patients were operated on, and two patients received an allogeneic hematopoietic stem cell transplantation (HSCT) (Tab. 2). Treatment protocols varied according to the time period of the diagnosis and type of malignancy. The majority of leukemia patients were treated according to Berlin-Frankfurt-Münster (BFM) based protocols while one respondent was cured after being treated according to the Nordic Society of Pediatric Hematology and Oncology (NOPHO) Acute Lymphoblastic Leukemia (ALL)
Study participants

\begin{tabular}{|l|l|l|}
\hline Males $(\mathbf{n}=\mathbf{1 7})$ & Females $(\mathbf{n}=\mathbf{1 7})$ & All $(\mathbf{n}=\mathbf{3 4})$ \\
\hline 27 & 25 & 27 \\
$(18-35)$ & $(18-31)$ & $(18-35)$ \\
\hline & & \\
14 & 14 & 14 \\
$(2-17)$ & $(12-18)$ & $(2-18)$ \\
\hline & & \\
13.5 & 15 & 14 \\
$(3-24)$ & $(5-24)$ & $(3-24)$ \\
\hline $6(35.3)$ & & \\
$7(41.2)$ & $7(36.8)$ & $13(36.1)$ \\
$1(2.8)$ & $8(47)$ & $15(44.1)$ \\
0 & 0 & $1(2.8)$ \\
$2(11.8)$ & $2(10.5)$ & $2(5.6)$ \\
$1(5.9)$ & 0 & $2(5.6)$ \\
& 0 & $1(2.8)$ \\
\hline
\end{tabular}

2008 guidelines. The treatment protocols are indicated in the Table 2 and are outlined in details in the Supplement 3 (available on https://journals.viamedica.pl/ginekologia_polska/issue). None of the survivors were irradiated on abdominal field, however nine respondents received cranial irradiation.

Review of the exposure to gonadotoxic drugs revealed significantly higher median cumulative CED in patients treated for solid tumors as compared to those treated for lymphoma and leukemia (6660 vs 4352 vs 3000 mg/m², respectively, $p=0.014$ ). According to the expectation in leukemia cohort CED was much higher in the recipients of allogeneic HSCT as compared to non-transplanted patients. Additionally, females affected by Hodgkin lymphomas were treated with dacarbazine (median cumulative dose was $2250 \mathrm{mg} / \mathrm{m}^{2}$ ) whereas platinum compounds were frequently added in solid tumors (the respective median cumulative dose for carboplatin and cisplatin was 1500 and $50 \mathrm{mg} / \mathrm{m}^{2}$, Tab. 2)

\section{Perception of the reproductive health in males}

The answers to the questions provided by the male survivors are summarized in Table 3 . All 17 respondents were able to get an erection and ejaculate, two survivors (11.8\%) reported problems with penetration (both were single at the time of evaluation). Ten young men (58.8\%) were married or had a partner, the remaining seven (41.2\%) were single at the time of assessment. The average sexual activity was three times per week (ranged from 0 to 10). The majority of males (94.1\%) felt normal sexual desire, on a ten-point scale the average libido score was nine (ranged from 3 to 10). Thirteen survivors (76.5\%) used contraception, preferably the barrier one. Notwithstanding, 14 out of 17 (82.4\%) did 


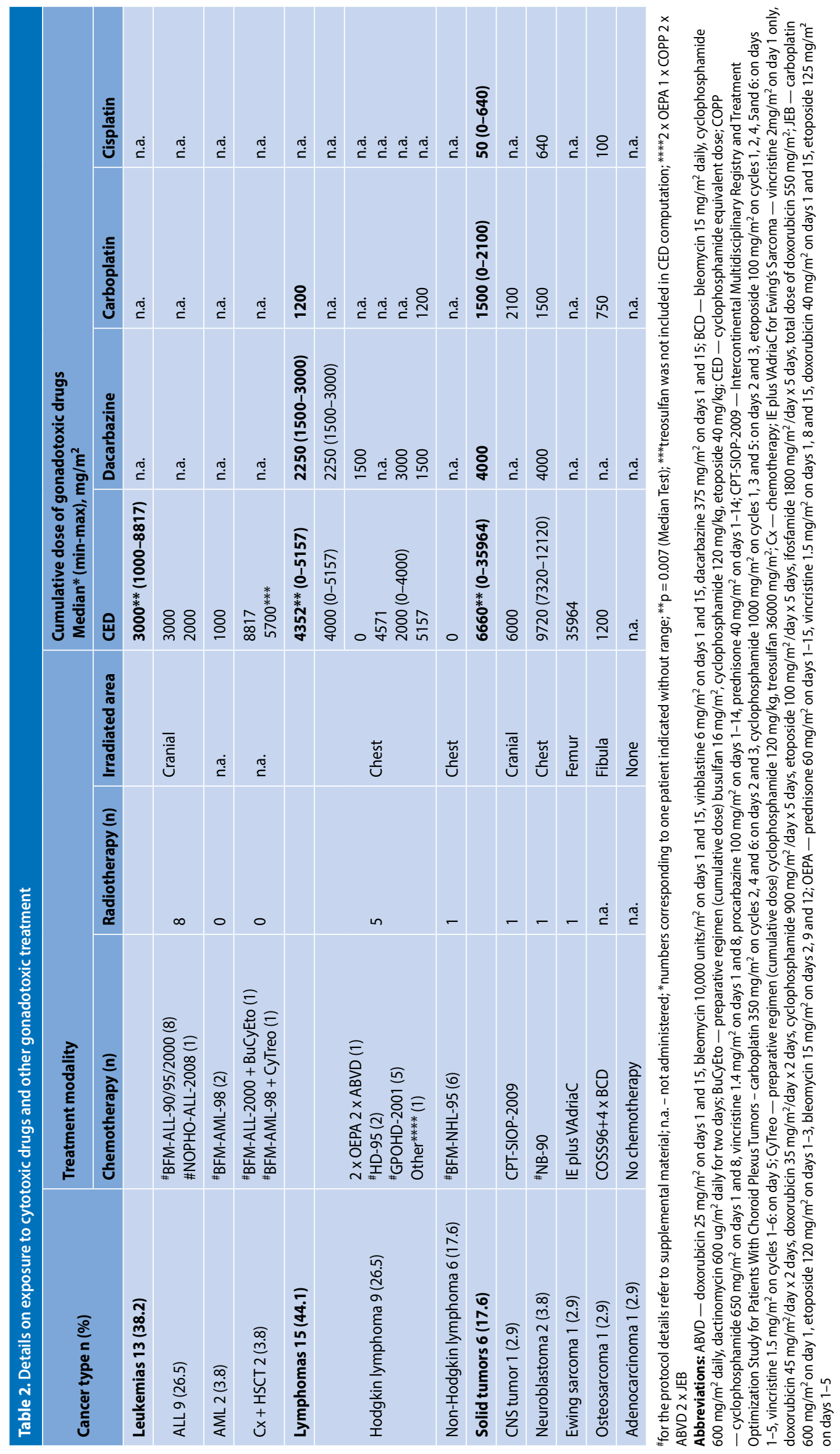


Table 3. Responses provided by the male survivors $(n=17)$

\begin{tabular}{|c|c|}
\hline Variable & $n(\%)$ \\
\hline $\begin{array}{l}\text { Feel sexual desire } \\
\text { Feel low sexual desire }\end{array}$ & $\begin{array}{l}16(94.1) \\
1(5.9)\end{array}$ \\
\hline $\begin{array}{l}\text { Able to get an erection } \\
\text { Unable to get an erection }\end{array}$ & $\begin{array}{l}17(100) \\
0(0)\end{array}$ \\
\hline $\begin{array}{l}\text { Able to ejaculate } \\
\text { Unable to ejaculate }\end{array}$ & $\begin{array}{l}17(100) \\
0(0)\end{array}$ \\
\hline $\begin{array}{l}\text { Able to insert penis into vagina } \\
\text { Unable to insert penis into vagina }\end{array}$ & $\begin{array}{l}15(88.2) \\
2(11.8)\end{array}$ \\
\hline $\begin{array}{l}\text { Have a partner } \\
\text { No partner }\end{array}$ & $\begin{array}{l}10(58.8) \\
7(41.2)\end{array}$ \\
\hline Sexual activities per week, median (min-max) & $3(0-10)$ \\
\hline Libido*, median (min-max) & $9(3-10)$ \\
\hline $\begin{array}{l}\text { Do not use contraception } \\
\text { Use contraception } \\
\text { Barrier contraceptives } \\
\text { Coitus interruptus } \\
\text { Contraception used by partner }\end{array}$ & $\begin{array}{l}4(23.5) \\
13(76.5) \\
10(76.9) \\
1(7.7) \\
2(15.4)\end{array}$ \\
\hline $\begin{array}{l}\text { Trying to conceive at the moment, } \\
\text { Not trying to conceive at the moment }\end{array}$ & $\begin{array}{l}3(17.7) \\
14(82.4)\end{array}$ \\
\hline Time trying to conceive (months), median (min-max) & $1(1-12)$ \\
\hline $\begin{array}{l}\text { Have biological children } \\
\text { Do not have biological children }\end{array}$ & $\begin{array}{l}4(23.5) \\
13(76.5)\end{array}$ \\
\hline Time to conceiving (months), median (min-max) & $2(1-16)$ \\
\hline $\begin{array}{l}\text { Partner has children } \\
\text { Did not know if the partner has children } \\
\text { Partner does not have children }\end{array}$ & $\begin{array}{l}1(5.9) \\
6(35.3) \\
10(58.8)\end{array}$ \\
\hline $\begin{array}{l}\text { Azoospermic in semen analysis } \\
\text { Did not undergo semen analysis }\end{array}$ & $\begin{array}{l}2(11.8) \\
15(88.2)\end{array}$ \\
\hline $\begin{array}{l}\text { Received chemotherapy during adulthood } \\
\text { Received radiotherapy during adulthood } \\
\text { Take medication constantly }\end{array}$ & $\begin{array}{l}2(11.8) \\
1(5.9) \\
2(11.8)\end{array}$ \\
\hline $\begin{array}{l}\text { Close** relatives had fertility problems } \\
\text { Close** relatives did not have fertility problems }\end{array}$ & $\begin{array}{l}1(5.9) \\
16(94.1)\end{array}$ \\
\hline
\end{tabular}

*scored from 1 to 10; **defined as grandfather, father, brother, cousin

not intend to conceive and did not have biological children $(67.5 \%)$ at the time of the evaluation. The median time of conception after cessation of contraceptives in four males (23.5\%) who had offspring was two months (range 1-16). Three males had one child each, one survivor had two healthy children. Two respondents (11.8\%) underwent semen analysis, both were found to be azoospermic. Both were married or had a partner, one survivor was trying to conceive. One of the azoospermic males was treated for Ewing's sarcoma, diagnosed at 15 years of age (CED $35964 \mathrm{mg} / \mathrm{m}^{2}$ ), another one - for Hodgkin's lymphoma, diagnosed at 12 years of age (CED $4571 \mathrm{mg} / \mathrm{m}^{2}$ ). Another patient reported concerns potentially affecting reproductive health was chemo- and radiotherapy received beyond 18 years of age, one suffered from parotitis during childhood and one male reported impaired fertility as a family problem.
Table 4. Responses provided by the female survivors $(n=17)$

\begin{tabular}{|c|c|}
\hline Variables & $n(\%)$ \\
\hline $\begin{array}{l}\text { Normal puberty } \\
\text { Delayed puberty }\end{array}$ & $\begin{array}{l}15(88.2) \\
2(11.8)\end{array}$ \\
\hline Age of menarche, median (min-max) & $14(12-17)$ \\
\hline $\begin{array}{l}\text { Regular menstrual cycle } \\
\text { Irregular menstrual cycle }\end{array}$ & $\begin{array}{l}12(70.6) \\
5(29.4)\end{array}$ \\
\hline $\begin{array}{l}\text { Have a partner } \\
\text { Divorced } \\
\text { No partner }\end{array}$ & $\begin{array}{l}10(58.8) \\
2(11.8) \\
5(29.4)\end{array}$ \\
\hline Sexual activities per week, median (min-max) & $1(0-9)$ \\
\hline Libido*, median (min-max) & $5(0-10)$ \\
\hline $\begin{array}{l}\text { Do not use contraception } \\
\text { Use contraception } \\
\text { Barrier contraceptives } \\
\text { Hormonal contraceptives } \\
\text { Coitus interruptus } \\
\text { All types of contraceptives } \\
\text { No answer }\end{array}$ & $\begin{array}{l}8(47.1) \\
7(41.2) \\
3(42.9) \\
2(28.6) \\
1(14.3) \\
1(14.3) \\
2(11.8)\end{array}$ \\
\hline $\begin{array}{l}\text { Have biological children } \\
\text { Do not have biological children }\end{array}$ & $\begin{array}{l}7(41.2) \\
10(58.8)\end{array}$ \\
\hline Time to conceive (months), median (min-max) & $3(1-8)$ \\
\hline $\begin{array}{l}\text { Partner has children } \\
\text { Partner does not have children } \\
\text { The partner has never had another partner } \\
\text { Has never have sexual relation }\end{array}$ & $\begin{array}{l}2(11.8) \\
10(58.8) \\
3(17.6) \\
2(11.8)\end{array}$ \\
\hline $\begin{array}{l}\text { Experienced some fertility concerns } \\
\text { No fertility problems }\end{array}$ & $\begin{array}{l}2(11.8) \\
15(88.3)\end{array}$ \\
\hline $\begin{array}{l}\text { Had gynecological problems } \\
\text { Did not have gynecological problems }\end{array}$ & $\begin{array}{l}3(17.6) \\
14(82.4)\end{array}$ \\
\hline $\begin{array}{l}\text { Have been treated for infertility } \\
\text { Treated with hormonal replacement therapy } \\
\text { Close }{ }^{* *} \text { relatives had fertility problems }\end{array}$ & $\begin{array}{l}0 \\
0 \\
0\end{array}$ \\
\hline $\begin{array}{l}\text { Received chemotherapy during adulthood } \\
\text { Received radiotherapy during adulthood } \\
\text { Take medication constantly }\end{array}$ & $\begin{array}{l}2(11.8) \\
1(5.9) \\
4(23.6)\end{array}$ \\
\hline
\end{tabular}

*scored from 1 to 10 ; **defined as sister, mother, grandmother

\section{Perception of the reproductive health in females}

The responses of female survivors are summarized in Table 4. Two (11.8\%) out of 17 females reported delayed puberty. Median age of menarche was $14(12-17)$ years - slightly delayed as compare to healthy Lithuanian population (13.5 years) [15]. Twelve (70.6\%) participants had regular menstrual cycles, whereas 5 (29.4\%) reported irregular bleeding. More than half of respondents (58.8\%) were married or had a partner. Females reported median 1 (0-9) sexual activity per week, and $5(0-10)$ points of libido on average. Seven (41.2\%) survivors succeeded to conceive with a median time of conception was three [1-8] months after cessation of contraception. Eight (47.1\%) females did not use any methods to avoid conception while the other half used different contraceptives (Tab. 4). The pregnancies terminated in seven full term pregnancies and three 
miscarriages. Only two (11.8\%) females reported fertility problems. However, gynecological concerns such as pelvic adhesion, polycystic ovarian syndrome, uterine leiomyomas /fybroids were more frequent. One participant suffered/ from a sexually transmitted disease, another one underwent surgeries of the uterus or ovaries. None of the participants were treated for infertility or sought for assisted reproduction, hormonal replacement therapy (HRT) or had family history of infertility. Two (11.8\%) females reported having received chemotherapy or radiotherapy beyond the age of 18 . Four respondents took daily medicines: Two (11.8\%) were taking L-Thyroxine (both of them had children), one - beta blockers, the fourth one was on immunoglobulin replacement therapy due to a secondary immune deficiency following HSCT.

\section{DISCUSSION}

The current study is the first attempt to address the quality of reproductive health in Lithuanian childhood cancer survivors. The crosscut survey aimed at capturing impairments of reproductive health in a specific cohort of childhood cancer survivors known to have long-term late effects related to cancer treatment.

The most relevant limitation of our study is a low number of survivors who reported their experiences. The obtained results derived only from 34 out of 346 (9.8\%) addressed survivors who fulfilled the questionnaires. More than half of the consignees $(190,54.9 \%)$ received the questionnaire but did not wish to participate in the survey. This fact raises a concern of feasibility to address such a delicate issue as reproductive and sexual health in childhood cancer survivors many years after treatment - the median follow-up of the respondents was 14 years. One could speculate that those who did have sexual or fertility worries were reluctant to disclose them or opted for the'right to be forgotten' [16]. The stigma of cancer is still prevalent and many survivors prefer to avoid sharing their disease- or treatment-related experiences and its consequences. Some parents of very young children protected them from knowing that they were treated for cancer (personal experience), and presumably did not inform them about the mailed invitation. Other studies reported a variable response rate to the questionnaires regarding the reproductive function in childhood cancer survivors - the percentage of responders varied from $29.3 \%$ to $78.6 \%$ [13, 17-21]. A low response rate may suggest a response bias and limited ability to generalize the results. On the other hand, many survivors pointed out insufficient information on the impact of cancer treatment on fertility and its preservation options [6, 21-23]. Raising awareness of potential fertility harm after completion of therapy would facilitate the assessment of reproductive health in the future.
Of note, one third (34.7\%) of our survivors did not receive the mail due to demographic changes in the country - the emigration rate in Lithuania was the third highest in the European Union in 2017 [24], young emigrants (20-34 years) comprising the largest group [25]. A high number of citizens who left their home country reflected a global trend of extreme mobility of young people. Thus, a pan-European system of surveillance of pediatric cancer survivors such as Survivorship Passport [26] would enable to provide an appropriate and timely care to this vulnerable population across Europe. The implementation of this digital tool translated to several European languages would facilitate access to the information on treatment and recommendations of care independently of the living place, at least in Europe.

The second limitation of the study was a retrospective way to retrieve data on treatment. In contrast to the cancer type distribution in all survivors eligible for the study ( $n=346$ ) who were treated mostly for leukemia [n $=165$ (47.7\%), Supp. 2] in the responders' cohort lymphoma was the predominant diagnosis $[n=15$ (44.1\%), Table 1]. The documentation analysis was limited to the study participants' records. As a consequence, the treatment applied was quite heterogenous, especially in the solid tumor group. Thus, only a descriptive data review could be carried out. Nevertheless, even in such a small and heterogenous group we could demonstrate much higher exposure to gonadotoxic drugs expressed as a significantly higher median CED in solid tumors as compared to leukemia and lymphoma ( $p=0.014)$ as well as more complex treatment. Although there is no data comparing median CEDs across different types of childhood cancer, some studies have shown that solid tumors, particularly sarcomas, are treated with a high-dose alkylating agent therapy, which is related to males' infertility in the adulthood as well as treatment for Hodgkin lymphoma can cause infertility in males [17].

In our survey, the perception of sexual dysfunction among childhood cancer survivors was similar to that observed among healthy population: in males the rate of low sexual desire or difficulties in penetration did not exceed $11.2 \%$ that is comparable to the rate observed in young healthy Lithuanian males [27]. The results differ from data reported by other groups showing high prevalence of sexual dysfunction in childhood cancer survivors $[28,29]$. The inconsistency is most probably attributable to a non-response bias as discussed above. There are no data on exact prevalence of infertility among healthy Lithuanian population. Datta et al., reported an infertility rate of $12.5 \%$ among healthy women and $10.1 \%$ among men in Britain [30]. According to World Health Organization, global infertility prevalence rates are difficult to determine, however, approximately one in every four couples in developing countries had been found to be affected by 
infertility [31]. Specifically, adult cancer survivors encounter reproductive health worries as well - womens' pregnancy rates are quite low [32]. It seems that the adverse effect of systemic treatment was strongly related with a patient's age [33], therefore childhood cancer survivors are exposed at increased risk of infertility. Males are in a higher risk for hypogonadism and sexual dysfunction [34]. Both male and female survivors lacked knowledge about infertility and underestimated the risk of infertility [35]. In our study only few males had biological children and attempted to conceive probably due to the young age of the respondents (median current age was 25 years). However, in this small cohort study, two males were azoospermic, both were treated with high cumulative doses of gonadotoxic drugs, CED $\geq 4000 \mathrm{mg} / \mathrm{m}^{2}$, which is known to be related to impaired spermatogenesis [17].

The percentage of men having low semen quality in male childhood cancer survivors (11.8\%) are in parallel with semen quality of young men from the general population in Baltic countries (11-15\% of them have low semen quality) [36]. Our study replicated the data published by other study groups who found that infertility was most prevalent among male survivors treated for sarcomas and Hodgkin lymphoma. In addition, the risk of permanent sterility was especially high when the cumulative dose of cyclophosphamide was greater than $7.5 \mathrm{~g} / \mathrm{m}^{2}[17,37]$. This finding raises a concern that the number of azoospermic survivors could be higher if semen analysis was offered as a routine follow-up investigation and points out on the relatively easy preservation of fertility in male adolescents.

Only a few of female participants reported delayed puberty, fertility-related or gynecological problems. None of the respondents was treated for infertility or used HRT, with $29.4 \%$ reported an irregular menstrual cycle. Few studies investigated the age of menarche of childhood cancer survivors. Some findings suggested that childhood cancer treatment including cranial radiation in girls resulted in a significantly earlier menarche [38]. Other stated that cranial irradiation appeared to have a minimal impact on the onset of puberty [39]. However, survivors of the central nervous system tumors appeared to be at significant risk of both early and late menarche associated with radiotherapy [40]. Our study did not include a comparison group, it would be insightful to compare reproductive health of survivors with their healthy siblings as it was done in some other studies $[14,41]$. Data from other studies showed that female survivors are at a future risk of premature menopause (before 40 years) [42-44], they also had an increased risk of clinical infertility ( $>1$ year of attempts at conception without success) compared to siblings [41]. Our current study did not include a hormonal analysis that could have given a better estimation of the prevalence of sexual dysfunction. Other similar studies found that cancer survivors had significantly lower anti-Müllerian hormone and higher follicle-stimulating hormone levels [19, 45-48].

In addition, psychosexual and social problems of childhood cancer survivors could be taken into account as they were reported in other studies, such as lower rates of marriage and parenthood, delayed sexual intercourse, and concerns regarding the reproductive function $[49,50]$. As the study included the survivors treated more than a decade ago, none of them was appropriately informed about the impact of the treatment on reproductive health. The availability of fertility preservation techniques was quite limited at that time. Due to the dramatic changes occurred in current practice, prospective counseling on fertility preservation must be offered to all patients and their families.

\section{CONCLUSIONS}

To summarize, we found a low prevalence of sexual dysfunction, fertility related or puberty disorders in childhood cancer survivors, however, considering a low response rate, the results should be interpreted with caution. Potential azoospermia after high CED in male patients should imply mandatory fertility preservation before treatment whenever possible. This study is the first attempt to address the quality of reproductive health in Lithuanian childhood cancer survivors that unraveled important concerns to be improved in clinical practice. Implementation and equal access to fertility preservation techniques (e. g. cryopreservation of semen and ovarian tissue) should be prioritized to minimize adverse effect of infertility after cancer therapy. An appropriate counseling of all cancer patients and families on potential adverse effect of the treatment on reproductive health would facilitate a highly warranted prospective research in a larger scale in the future.

\section{Acknowledgments}

Not applicable.

\section{Conflicts of interest}

The authors declare no conflict of interest.

\section{Author contributions}

ESR wrote the manuscript, ZB and ZG designed female questionnaire, RA and GV designed male questionnaire, ESR, $\mathrm{MJ}$ and RV collected and retrieved the data, ESR, KZ and JR analyzed the data, JR conceptualized and supervised the study. All authors contributed to the study conception, bioethical approval, critically revised the manuscript, agreed and approved the final version for submission.

\section{Funding}

The study was supported by the Lithuanian Childhood Cancer Association "Paguoda" www.paguoda.It. 


\section{REFERENCES}

1. Winther JF, Kenborg L, Byrne J, et al. Childhood cancer survivor cohorts in Europe. Acta Oncol. 2015; 54(5): 655-668, doi: 10.3109/0284186X.2015.1008648, indexed in Pubmed: 25813473.

2. Ness K, Armstrong G, Kundu M, et al. Frailty in childhood cancer survivors. Cancer. 2014; 121(10): 1540-1547, doi: 10.1002/cncr.29211.

3. Zebrack $B J$, Foley $S$, Wittmann $D$, et al. Sexual functioning in young adult survivors of childhood cancer. Psychooncology. 2010; 19(8): 814-822, doi: 10.1002/pon.1641, indexed in Pubmed: 19862693.

4. Lee $\mathrm{SH}$, Shin CHo. Reduced male fertility in childhood cancer survivors. Ann Pediatr Endocrinol Metab. 2013; 18(4): 168-172, doi: 10.6065/apem.2013.18.4.168, indexed in Pubmed: 24904872.

5. Žulpaitè R, BumbulienėŽ. Reproductive health of female childhood cancer survivors. Ginekol Pol. 2018; 89(5): 280-286, doi: 10.5603/GP.a2018.0048, indexed in Pubmed: 30084481.

6. Kim J, Mersereau JE. A pilot study about female adolescent/young childhood cancer survivors' knowledge about reproductive health and their views about consultation with a fertility specialist. Palliat Support Care. 2015; 13(5): 1251-1260, doi: 10.1017/S147895151400114X, indexed in Pubmed: 25341555.

7. Lehmann V, Keim MC, Nahata L, et al. Fertility-related knowledge and reproductive goals in childhood cancer survivors: short communication. Hum Reprod. 2017; 32(11): 2250-2253, doi: 10.1093/humrep/dex297, indexed in Pubmed: 29040512.

8. van Dorp W, Haupt R, Anderson RA, et al. Reproductive Function and Outcomes in Female Survivors of Childhood, Adolescent, and Young Adult Cancer: A Review. J Clin Oncol. 2018; 36(21): 2169-2180, doi: 10.1200/JCO.2017.76.3441, indexed in Pubmed: 29874135.

9. Chow EJ, Stratton KL, Leisenring WM, et al. Pregnancy after chemotherapy in male and female survivors of childhood cancer treated between 1970 and 1999: a report from the Childhood Cancer Survivor Study cohort. Lancet Oncol. 2016; 17(5): 567-576, doi: 10.1016/S14702045(16)00086-3, indexed in Pubmed: 27020005.

10. Reinmuth S, Hohmann C, Rendtorff R, et al. Impact of chemotherapy and radiotherapy in childhood on fertility in adulthood: the FeCt-survey of childhood cancer survivors in Germany. J Cancer Res Clin Oncol. 2013; 139(12): 2071-2078, doi: 10.1007/s00432-013-1527-9, indexed in Pubmed: 24085598.

11. Kenney LB, Laufer MR, Grant FD, et al. High risk of infertility and long term gonadal damage in males treated with high dose cyclophosphamide for sarcoma during childhood. Cancer. 2001; 91(3): 613-621, doi: 10.1002/1097-0142(20010201)91:3<613::aid-cncr1042>3.0.co;2-r, indexed in Pubmed: 11169946.

12. Green DM, Nolan VG, Goodman PJ, et al. The cyclophosphamide equivalent dose as an approach for quantifying alkylating agent exposure: a report from the Childhood Cancer Survivor Study. Pediatr Blood Cancer. 2014; 61(1): 53-67, doi: 10.1002/pbc.24679, indexed in Pubmed: 23940101.

13. Chemaitilly W, Li Z, Krasin MJ, et al. Premature Ovarian Insufficiency in Childhood Cancer Survivors: A Report From the St. Jude Lifetime Cohort. J Clin Endocrinol Metab. 2017; 102(7): 2242-2250, doi: 10.1210/jc.20163723, indexed in Pubmed: 28368472.

14. Green DM, Zhu L, Wang M, et al. Effect of cranial irradiation on sperm concentration of adult survivors of childhood acute lymphoblastic leukemia: a report from the St. Jude Lifetime Cohort Studyt. Hum Reprod. 2017;32(6): 1192-1201, doi: 10.1093/humrep/dex082, indexed in Pubmed: 28444255.

15. Tutkuviene J. Growth and development criteria for Lithuanian children of various ages. Studies in Human Biology Edited by Bodzsar EB, Susanne C Budapest. ; 1996: 157-64.

16. Ploug T, Holm S. Meta Consent - A Flexible Solution to the Problem of Secondary Use of Health Data. Bioethics. 2016; 30(9): 721-732, doi: 10.1111/bioe.12286, indexed in Pubmed: 27628305.

17. Gilleland Marchak J, Seidel KD, Mertens AC, et al. Male infertility in long-term survivors of pediatric cancer: a report from the childhood cancer survivor study. J Cancer Surviv. 2014; 8(3): 437-447, doi: 10.1007/s11764-014-0354-6, indexed in Pubmed: 24711092.

18. Yoon JuY, Park HJ, Ju HY, et al. Gonadal and Sexual Dysfunction in Childhood Cancer Survivors. Cancer Res Treat. 2017; 49(4): 1057-1064, doi: 10.4143/crt.2016.197, indexed in Pubmed: 28161937.

19. van den Berg MH, Overbeek A, Lambalk CB, et al. DCOG LATER-VEVO study group. Long-term effects of childhood cancer treatment on hormonal and ultrasound markers of ovarian reserve. Hum Reprod. 2018; 33(8): 1474-1488, doi: 10.1093/humrep/dey229, indexed in Pubmed: 29982673.
20. Ritenour CWM, Seidel KD, Leisenring W, et al. Erectile Dysfunction in Male Survivors of Childhood Cancer-A Report From the Childhood Cancer Survivor Study. J Sex Med. 2016; 13(6): 945-954, doi: 10.1016/j. jsxm.2016.03.367, indexed in Pubmed: 27117527.

21. Benedict C, Thom B, Friedman D, et al. Young Adult Female Survivors' Unmet Information Needs and Reproductive Concerns Contribute to Decisional Conflict about Post-treatment Fertility Preservation. Cancer. 2016; 122(13): 2101-9.

22. Angarita AM, Johnson CA, Fader AN, et al. Fertility Preservation: A Key Survivorship Issue for Young Women with Cancer. Front Oncol. 2016; 6: 102, doi: 10.3389/fonc.2016.00102, indexed in Pubmed: 27200291.

23. Chapple A, Salinas M, Ziebland S, et al. Fertility issues: the perceptions and experiences of young men recently diagnosed and treated for cancer. J Adolesc Health. 2007; 40(1): 69-75, doi: 10.1016/j.jadohealth.2006.07.010, indexed in Pubmed: 17185208.

24. Haavisto A, Henriksson M, Heikkinen $R$, et al. Sexual function in male long-term survivors of childhood acute lymphoblastic leukemia. Cancer. 2016; 122(14): 2268-2276, doi: 10.1002/cncr.29989, indexed in Pubmed: 27171363.

25. Gunn HM, Rinne I, Emilsson H, et al. Primary Gonadal Insufficiency in Male and Female Childhood Cancer Survivors in a Long-Term Follow-Up Clinic. J Adolesc Young Adult Oncol. 2016; 5(4): 344-350, doi: 10.1089/jayao.2016.0007, indexed in Pubmed: 27195593.

26. Haupt R, Essiaf S, Dellacasa C, et al. PanCareSurFup, ENCCA Working Group, ExPo-r-Net Working Group. The'Survivorship Passport'for childhood cancer survivors. Eur J Cancer. 2018; 102: 69-81, doi: 10.1016/j. ejca.2018.07.006, indexed in Pubmed: 30138773.

27. Matulevicius V, Ostrauskas R, Preikša $T$, et al. Sexual function of Lithuanian males aged 26-36 years. Sexual Medicine. 2013; 1(1): 7-14.

28. Yoon JuY, Park HJ, Ju HY, et al. Gonadal and Sexual Dysfunction in Childhood Cancer Survivors. Cancer Res Treat. 2017; 49(4): 1057-1064, doi: 10.4143/crt.2016.197, indexed in Pubmed: 28161937.

29. Ritenour CWM, Seidel KD, Leisenring W, et al. Erectile Dysfunction in Male Survivors of Childhood Cancer-A Report From the Childhood Cancer Survivor Study. J Sex Med. 2016; 13(6): 945-954, doi: 10.1016/j. jsxm.2016.03.367, indexed in Pubmed: 27117527.

30. Datta J, Palmer MJ, Tanton C, et al. Prevalence of infertility and help seeking among 15000 women and men. Hum Reprod. 2016; 31(9): 21082118, doi: 10.1093/humrep/dew123, indexed in Pubmed: 27365525.

31. WHO | Global prevalence of infertility, infecundity and childlessness [updated 2020/03/02/18:30:01]. Available from: https://www who int/reproductivehealth/topics/infertility/burden/en.

32. Gerstl B, Sullivan E, Koch J, et al. Reproductive outcomes following a stem cell transplant for a haematological malignancy in female cancer survivors: a systematic review and meta-analysis. Support Care Cancer. 2019; 27(12): 4451-4460, doi: 10.1007/s00520-019-05020-8, indexed in Pubmed: 31541306.

33. Silva C, Ribeiro Rama AC, Reis Soares $S$, et al. Adverse reproductive health outcomes in a cohort of young women with breast cancer exposed to systemic treatments. J Ovarian Res. 2019; 12(1): 102, doi: 10.1186/s13048019-0581-6, indexed in Pubmed: 31672154.

34. La Vignera S, Cannarella R, Duca Y, et al. Hypogonadism and Sexual Dysfunction in Testicular Tumor Survivors: A Systematic Review. Front Endocrinol (Lausanne). 2019; 10: 264, doi: 10.3389/fendo.2019.00264, indexed in Pubmed: 31133982.

35. Huang SM, Tseng LM, Lai JCY, et al. Infertility-related knowledge in childbearing-age women with breast cancer after chemotherapy. Int J Nurs Pract. 2019; 25(5): e12765, doi: 10.1111/ijn.12765, indexed in Pubmed: 31313445

36. Erenpreiss J, Punab M, Zilaitiene B, et al. Semen quality of young men from the general population in Baltic countries. Hum Reprod. 2017; 32(6): 1334-1340, doi: 10.1093/humrep/dex062, indexed in Pubmed: 28383690.

37. Meistrich ML, Wilson G, Brown BW, et al. Impact of cyclophosphamide on long-term reduction in sperm count in men treated with combination chemotherapy for Ewing and soft tissue sarcomas. Cancer. 1992; 70(11): 2703-2712, doi: 10.1002/1097-0142(19921201)70:11<2703::aid-cncr28 20701123>3.0.co;2-x, indexed in Pubmed: 1423201.

38. Noorda EM, Somers R, Leeuwen FEv, et al. Adult height and age at menarche in childhood cancer survivors. European Journal of Cancer. 2001; 37(5): 605-612, doi: 10.1016/s0959-8049(00)00438-x.

39. Mills J, Fears T, Robison L, et al. Menarche in a cohort of 188 long-term survivors of acute lymphoblastic leukemia. The Journal of Pediatrics. 1997; 131(4): 598-602, doi: 10.1016/s0022-3476(97)70069-6. 
40. Armstrong GT, Whitton JA, Gajjar A, et al. Abnormal timing of menarche in survivors of central nervous system tumors: A report from the Childhood Cancer Survivor Study. Cancer. 2009; 115(11): 2562-2570, doi: 10.1002/cncr.24294, indexed in Pubmed: 19309737.

41. Barton SE, Najita JS, Ginsburg ES, et al. Infertility, infertility treatment and achievement of pregnancy in female survivors of childhood cancer: a report from the Childhood Cancer Survivor Study cohort. Lancet Oncol. 2013; 14(9): 873-881, doi: 10.1016/S1470-2045(13)70251-1, indexed in Pubmed: 23856401

42. Sklar CA, Mertens AC, Mitby $P$, et al. Premature menopause in survivors of childhood cancer: a report from the childhood cancer survivor study. J Natl Cancer Inst. 2006; 98(13): 890-896, doi: 10.1093/jnci/djj243, indexed in Pubmed: 16818852

43. De Bruin ML, Huisbrink J, Hauptmann M, et al. Treatment-related risk factors for premature menopause following Hodgkin lymphoma. Blood. 2008; 111(1): 101-108, doi: 10.1182/blood-2007-05-090225, indexed in Pubmed: 17890454.

44. Levine JM, Whitton JA, Ginsberg JP, et al. Nonsurgical premature menopause and reproductive implications in survivors of childhood cancer: A report from the Childhood Cancer Survivor Study. Cancer. 2018; 124(5): 1044-1052, doi: 10.1002/cncr.31121, indexed in Pubmed: 29338081.
45. Thomas-Teinturier C, Allodji RS, Svetlova E, et al. Ovarian reserve after treatment with alkylating agents during childhood. Hum Reprod. 2015; 30(6): 1437-1446, doi: 10.1093/humrep/dev060, indexed in Pubmed: 25801499.

46. Elchuri SV, Patterson $B C$, Brown M et al. Low Anti-Müllerian Hormone in Pediatric Cancer Survivors in the Early Years after Gonadotoxic Therapy. J Pediatr Adolesc Gynecol. 2016; 29(4): 393-399, doi: 10.1016/j. jpag.2016.02.009, indexed in Pubmed: 26924632.

47. Lie Fo, Laven JSE, Hakvoort-Cammel FG, et al. Assessment of ovarian reserve in adult childhood cancer survivors using anti-Müllerian hormone. Human Reproduction (Oxford, England. 2009; 24(4): 982-90.

48. Brougham MFH, Crofton PM, Johnson EJ, et al. Anti-Müllerian hormone is a marker of gonadotoxicity in pre- and postpubertal girls treated for cancer: a prospective study. J Clin Endocrinol Metab. 2012; 97(6): 2059-2067, doi: 10.1210/jc.2011-3180, indexed in Pubmed: 22472563.

49. van Dijk EM, van Dulmen-den Broeder E, Kaspers GJL, et al. Psychosexual functioning of childhood cancer survivors. Psychooncology. 2008; 17(5): 506-511, doi: 10.1002/pon.1274, indexed in Pubmed: 17935145.

50. Langeveld NE, Stam H, Grootenhuis MA, et al. Quality of life in young adult survivors of childhood cancer. Support Care Cancer. 2002; 10(8): 579-600, doi: 10.1007/s00520-002-0388-6, indexed in Pubmed: 12436217. 